\title{
LIVEABILITY AND PUBLIC SPACE IN CANBERRA'S SUBURBAN DEVELOPMENTS
}

\author{
MUMINOVIC MILICA \\ Faculty of Arts and Design, University of Canberra, Australia
}

\begin{abstract}
Almost all sustainable theories agree that to be sustainable suburbia needs to increase density and thus become aligned with urban spaces, focusing mainly on energy efficiency and transport. Even though suburbia represents one of the least sustainable spaces in the city, it remains one of the most desirable spaces for living. People choose to live in suburbs, new suburbs are built and old suburbs are preserved. The liveable aspects of suburbia are being ignored in theoretical arguments around sustainability. Using the case of Canberra, this paper aims to discuss liveability of suburbia as part of its sustainable development. Suburbia represents an important aspect of every city in Australia, particularly Canberra. With a strong commitment to being sustainable, we believe that this context represents a good place to test some of the ideas around sustainable suburbia. This paper tests the hypothesis that public green spaces are essential in discussing the liveable aspects of suburbia that can be employed to further explore sustainability. The research compares new sustainably-developed suburb and old suburban spaces to discuss liveable aspects and the connection with green spaces. The analysis uses morphological characteristics of the built environment and mapping with ArcGIS software. The results show that older suburbs had predominantly larger plots of land and smaller floor area ratio. The houses obtained link with the ground through a private garden at the back. On the other hand, with market pressure, contemporary suburban developments, even those claiming to be sustainable, are reducing the size of plots and losing the connection with the green. The paper concludes that sustainable developments are focusing mainly on densification of suburbia and liveability aspects are lost. We confirm that for achieving sustainability we need to consider public green spaces, their morphology and structure.
\end{abstract}

Keywords: suburban, sustainability, public, green, liveability.

\section{INTRODUCTION}

Although sustainability is exhausted concept due to its wide application and one might argue misuse, the aspirations behind that concept are significant. Most of the cities today have adopted various aspects of sustainability as part of their development agendas. While there is an agreement on the general direction towards more sustainable future, there is no single way how to achieve that [1]. There are numerous approaches to sustainability of our cities and lack of consistency in measurements of those achievements. The questions on how successful cities are on their targeted goals remain debatable.

The growth of urban population is continuing to transform cities around the world and urging planning actions that are going to secure more sustainable development [2]. Since cities are already having large footprints and dealing with the problems of sprawl, future growth will request transformation of existing built environment in cities. The predictions for population increase in Australia are significant, expecting doubling the current population in next fifty to sixty years [3]. Considering the current form of Australian largest cities, one of the important spaces of transformation in next decades will be suburbia [4], [5].

Canberra is ninth largest city in Australia and continues to grow, however the low population density is maintained with new suburbs being erected. Suburbs are considered to be the most desirable places to live and places where Australian identity is generated [6]. The public identifies suburbia to offering an important level of freedom and liveability. Since suburbia is defined as the least sustainable type of the spaces in cities and with the predicted 
growth of population, these suburban spaces become important places for retrofitting and will need to consider the ways in which they will be transformed to capture the future cities' growth [7]. Suburban way of life is less efficient as it promotes low-density living, monofunctional spaces, and thus car dependence.

Another important aspect of future development is liveability. The concept is not less ambiguous than sustainability. Both terms define the desirable quality of life in cities and in the same time are difficult to measure. There are numerous definitions of liveability. The most broad and common definition of liveability is on the subject of the quality of life [8] that has social aspects of interaction between people as well as interaction between people and environment. Most often the discussions are around urban liveability which is concerned with the characteristics of build environment, such as aesthetics as well as efficient transportation, compact neighbourhoods, human scale, public spaces and community life [9]. In the broadest sense, some of those characteristics are concerning the sustainability as well. There are some attempts to merge together the two aspects in rating systems for cities, generating a new composite assessment to combine liveability and environmental impact [10]. However, the way in which those characteristics of the cities are approached are very often quite different. Interestingly in some of the cases liveability is contrasting the concepts of sustainability. Some aspects of liveability comprise factors of consumption thus, the more liveable cities the more unsustainable they become, when considered energy efficiency [11]. One of those might be argued to be suburbia.

Sustainability agendas are urging for suburbs to be densified, however few of the projects are convincingly responding to that. There are numerous reasons for suburbs not being retrofitted, some of the most prominent are related to the diversity of the landownership, understanding of the possibilities for individual owners, market failures and processes [12]. There is a lot of opposition to changes in suburbia. The connections to green and private spaces as well as peace and quiet mostly residential neighbourhoods are most prominent topics around the liveable aspects of suburbia that people aim to preserve.

If we consider sustainability as a concept beyond energy efficiency, then the aspects of liveability in current plans for transformation of suburbia need to be included. Thus, this paper opens a discussion about sustainability and liveability of suburbia asking the question: what is the role of open public spaces for sustainability and liveability of suburbia? The aim of the paper is not to fully explore all the aspects of sustainability and liveability, but the contested aspects of densification and relationship with the green spaces. The paper explores three neighbourhoods in Canberra, Australia and compares their approaches to sustainability and liveability. Firstly, the paper sets the context for analysis and introduces Canberra's urban condition in respect to sustainability and liveability. Walkability scores have been applied to open discussion on dialectics between liveability and sustainability. Secondly the paper presents three case studies and explores the importance of public green spaces for sustainability and liveability and concludes with the overview of the relationships between morphology of public spaces, density and continuity of built environment. This paper is not observing the sustainability as a holistic concept but focuses on only one aspect of sustainability, density and compactness, two elements considered to be missing in current approach to suburbs.

\section{CANBERRA THE CITY OF SUBURBS}

Canberra is a planned city based on Garden City principles and city beautiful movement. Both theories have focused on the relationship with landscape and incorporating green spaces in the city. Landscape is important element in Australian cities that equates and serves as basis for their identity. Canberra is also known as the "Bush Capital" [13]. This aspect of its 
identity is recognised as one of important elements to be preserved and built on [14]. Connection to the landscape is built in decentralised organisation of the city and suburban low-density residential areas. It is considered as positive aspect that contributes to the quality of life, and suburbia is defined as place where Australian identity is developing [6].

Garden city idea was therefore well accepted in the planning and development of Australian cities. The Garden city concept emerged as a response to overcrowdings and densification of industrial cities in Europe at the beginning of 20th century [15]. The idea was to generate more liveable spaces that are going to merge positive aspects of rural and urban dwelling [16]. The connection to green spaces has always been understood as contributing to the quality of life. The proposal for Garden city was to organise built environment around centres that would generate a polycentric structure of the city as part of its growth, however in Canberra the idea of centre was never fully developed [17]. Although each suburb has a centre with local shops, the programs that they offer are limited. Most of the everyday activities need to happen outside of local suburbs.

There is little agreement on liveability of Canberra. Although ranking systems are questionable in their methodologies for evaluation and various aspects of quantitative and qualitative data that they apply [18], this paper acknowledges that, and uses ranking as an approach to jointly discuss liveability and sustainability. Since this research focuses on fine grain scale of suburbs and their approaches to sustainability, the paper explores differences in liveability in those suburbs. As the only liveability ranking system focused on individual suburbs in Canberra, the research uses "walkability index" to open discussion on how people perceive the positive and negative aspects of everyday life. This index identifies neighbourhoods that are encouraging walking and are providing "access to public transit, better commutes, and proximity to the people and places..." and those places ".... are the key to a happier, healthier and more sustainable lifestyle" [19]. Thus, it might be argued that more walkable neighbourhoods are also providing more liveable and sustainable environments. According to this index, Canberra is ranked as car dependant city, and positions on a tenth place among Australian cities.

Even though Canberra has very low walkability score on average, not all the suburbs have the same level being car dependent. Some of the suburbs have better walkability aspects, such as the central areas on the Northern Canberra Civic and Braddon. Since Canberra has strong agenda for sustainability and liveability of which density and connection to nature are most important elements [20], [21], this research uses three suburbs to explore the proposed questions. The selection of case studies is based on the sustainability agendas and liveability. We have chosen two suburbs built in response to sustainability and densification agendas adopted after 2004 and the third suburb follows pre-sustainability concerns and is located in the proximity of the previous two suburbs (Fig. 1).

Another element that has been applied in the selection of the case studies is the recent development of suburb in Canberra that aims to be "the happiest suburb in Australia" [22]. Crace is newly designed suburb that has as an overarching agenda of "sustainability, health and happiness" [23]. The construction of the suburb began in 2009 and current population is 4,459 ranging as average suburb in Canberra with 1,679 individual dwellings [24], the suburb has a long-term target to become carbon neutral [25].

The second selected suburb is Harrison. Harrison is located next to the Gungahlin town centre and built under the sustainability agenda in Canberra's spatial plan, which offers higher density living and mixed-use built environment. The suburb has large population however density is at average for Canberra. It has two primary schools, early childhood centre and hospital as well as local shop and restaurant facilities usually located in every suburb. The third selected suburb is Palmerston the one of the oldest suburbs in Gungahlin area, 


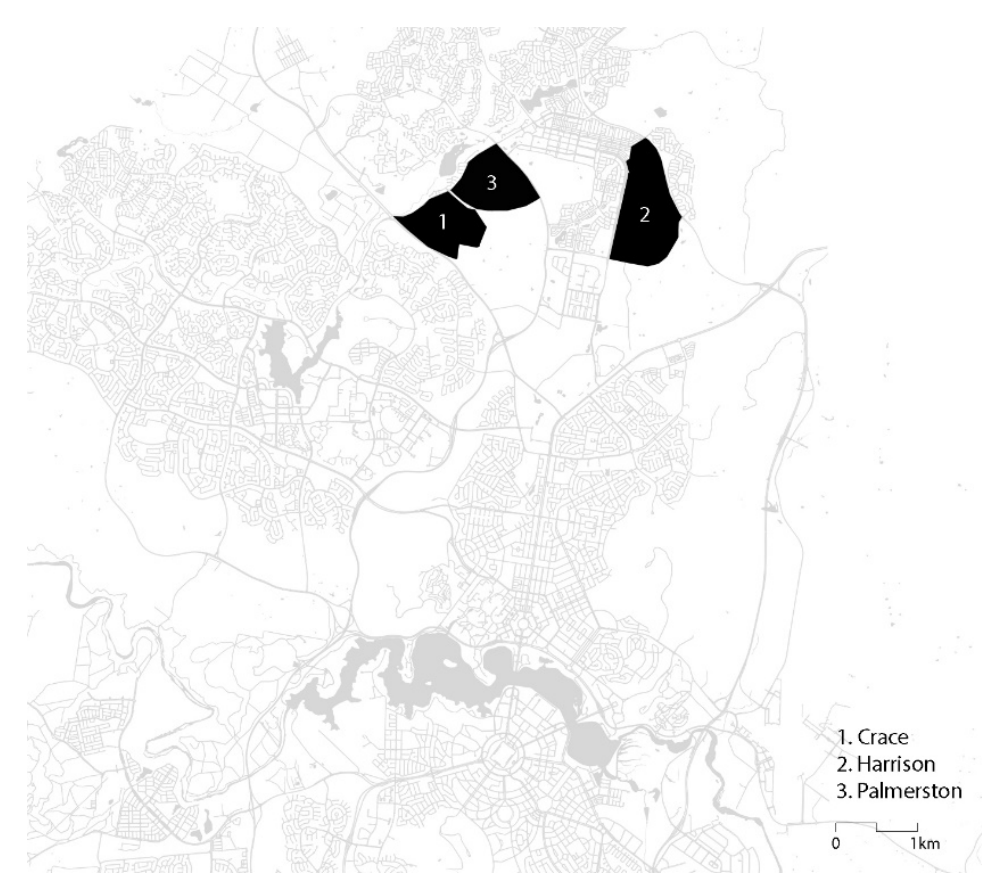

Figure 1: Position of the selected suburbs in Canberra. (Source: Author, based on Geospatial Data Open Catalogue, 2018.)

established in 1994 and developed second just after Mitchell. It is dominantly residential area with a local primary school and small shopping, community and medical centres.

All three suburbs are located close to the Gungahlin, which is considered as central commercial and transportation node for Northern Canberra. Crace is 93rd on the list of walkability index in Canberra with Walk Score 18, meaning that the neighbourhood is car dependant. Harrison has even lower walkability score as the least walkable suburb in Canberra with Walk Score of 15. Palmerston is also considered as car dependent suburb, however with slightly better outcome rating compared with the previous two suburbs, resulting in the 70th position with Walk Score of 29, thus resulting with better liveability indicators [19].

\section{METHODS}

The current definitions of the sustainable cities are looking at the compact cities [26] that will bring higher density and enable public transport, better facilities and reduce the travelling distances. Most of the strategies are thus focusing on generating more dense suburbia. Canberra has also adopted some of those aspects in the general plan [20]. Therefore, to analyse the aspects of sustainability of selected case studies the paper quantifies population density and focuses on built environment through analysis of the types of residential buildings (single family house, townhouse and apartment building). Compact neighbourhoods define not only high-density built environment, but also aspects of continuity and connectedness of built environment. Continuity and connectedness of built environment is defined as indicator of sustainability as it creates qualities of accessibility and mobility in space. 
Liveability definitions are outlining the aspects that are focusing on the quality of life. These aspects consider not only built environment but also economic and social elements. In this paper we are focusing on built environment and thus intangible aspects of liveability are omitted from the analysis. The quality of life is usually measured through built environment characteristics as well as efficient transportation, compact neighbourhoods, human scale, public spaces and community life. The potential for community life is explored in this paper as relationships between private and public spaces. The quantity and distribution of public space can indicate potential for socialising and strengthening community. The liveability aspect of interaction between people and environment is analysed through morphology and quantity of public green spaces. The analysis uses types of the street section and structure of the public private interface to discuss human scale.

The analysis is conducted in two stages. The paper explores firstly sustainability characteristics of all three neighbourhoods. These are summarised through density and quantification of types of the residential buildings. The compactness of the built environment is considered through the relationship with the open green spaces. The second stage focuses on indicators of liveability. This includes the quantity and structure of open green spaces, street section typology, its distribution and quantity. The three suburbs are analysed using ArcGIS program to map and quantify the data. Data are deriving from fieldwork observations and ACT Government Open Geospatial Data [27].

\section{THE LIVEABILITY AND SUSTAINABILITY RESULTS}

\subsection{Sustainability in Crace, Harrison and Palmerston}

The most populated within three analysed suburbs is Harrison, however Palmerston is the densest. Even though it was developed before the Canberra Spatial Plan (2014) that includes sustainability agenda and does not apply emblematic high-density types (high-rise buildings), it still manages to generate similar density as newly built sustainable suburbs. On the other hand, Palmerston also has the least open public green space available. Overall Palmerston has only 12 ha compared with Crace with 43 ha and Harrison 84ha. According to the ACT standards suburb should have at least 3 ha per 1000 people, meaning that Palmerston is below that standard and Crace and Harrison are exceeding the minimum open spaces (in case of the Crace more than three times and in case of the Harrison double of the necessary amount of open green space). The distribution of the open green spaces also varies (Fig. 2). Crace has majority of the open green spaces at the border of the suburb with one large park at the middle. Most of the green space is linear, creating continuous and homogeneous built environment. Harrison's open green public spaces are located throughout the suburb with large areas of open space that separate the suburb into smaller clusters. Vast open green spaces are generating discontinuity in built environment. There is also less connectedness of open green spaces contributing to isolated experience of public space. Palmerston has the least open public green space, most of which is in the central area of the suburb, and it is linear. There is only one smaller park located in the south east side of the suburb. The park is also disconnected from the central linear public space (Fig. 3). Fairly small ratio of green space in Palmerston does not affect the compactness of built environment. Crace and Palmerston have fairly compact built environments while Harrison can be separated in three major areas discontinued with large amounts of green spaces.

The fact that Palmerston does not have large amount of open public space has been overcame within a connection with the private gardens. Similar in density as other suburbs, Palmerston has overcome the reduction public spaces with the quantity of the private green 

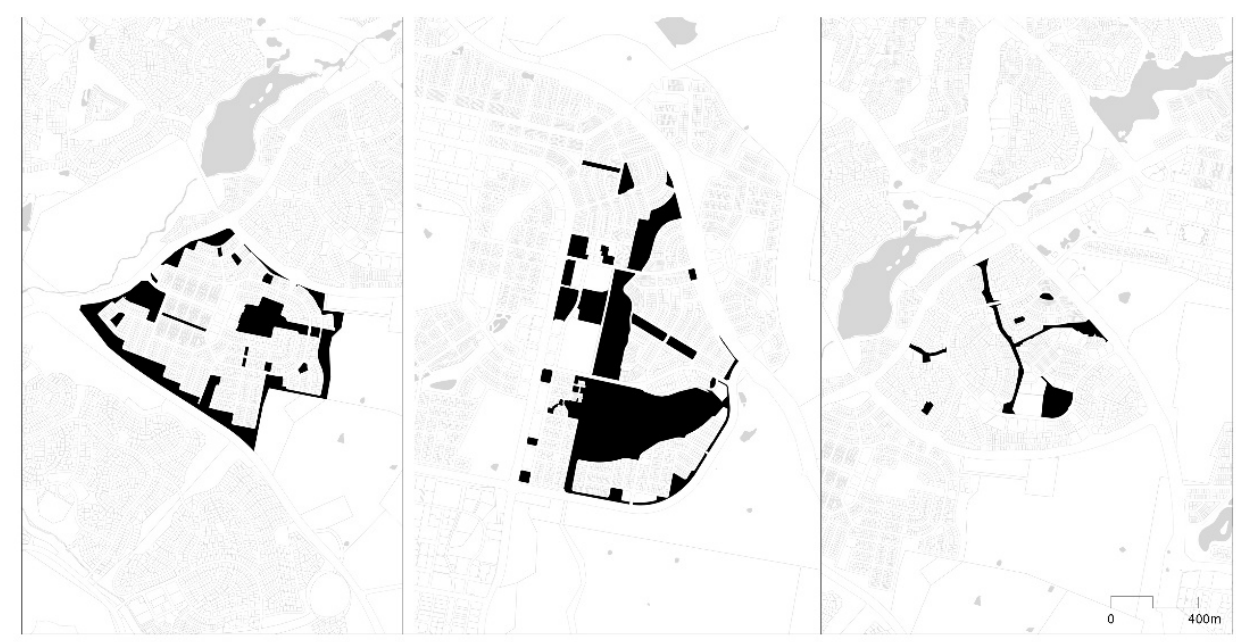

Figure 2: Green open spaces in (from left) Crace, Harrison, Palmerston. (Source: Author, based on Geospatial Data Open Catalogue, 2018.)
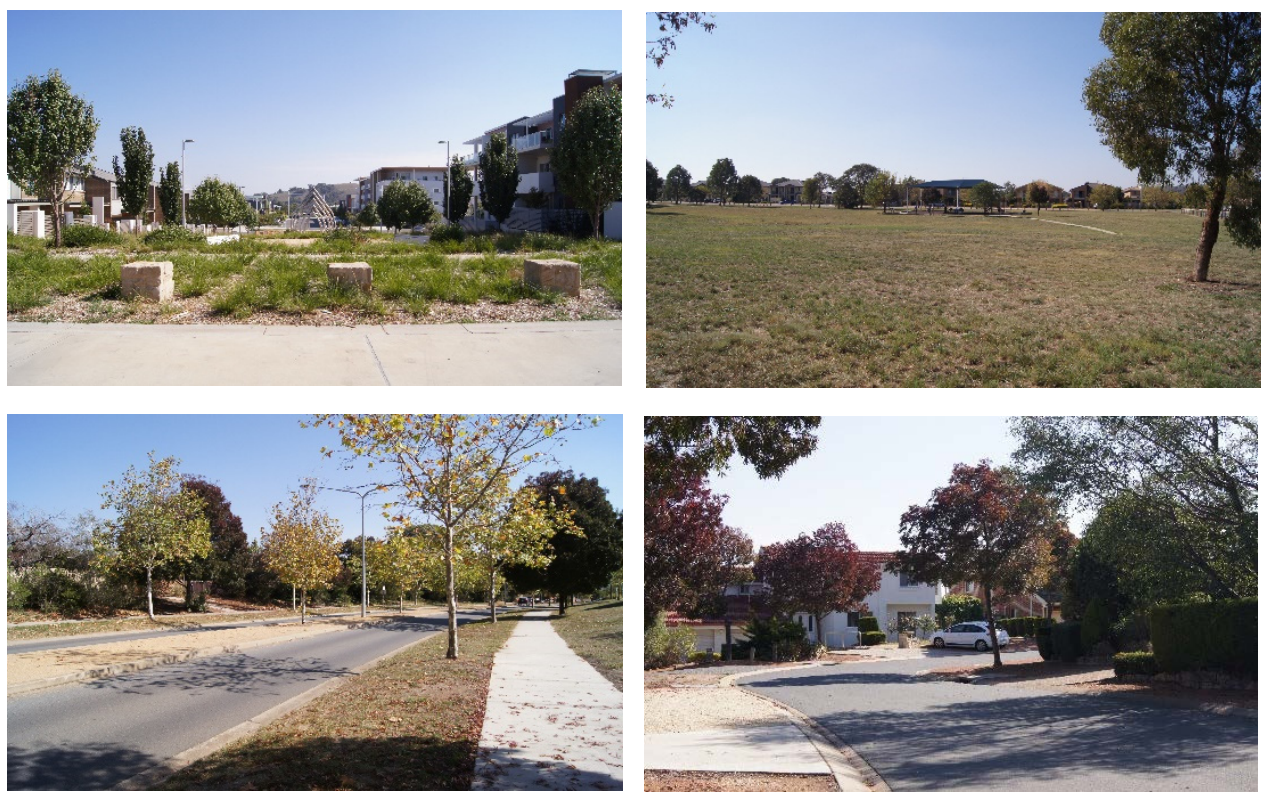

Figure 3: Public open green space in Crace and Harrison (top) and public and private open green space in Palmerston (bottom). (Source: Author, 2018.)

spaces. Palmerston has dominantly single family and townhouse types of residential buildings. The average plot size in Palmerston is $660 \mathrm{~m}^{2}$ with the range from 230 to $3000 \mathrm{~m}^{2}$. Compared with the Crace with the average plot size $432 \mathrm{~m}^{2}$ (as small as 130 to $885 \mathrm{~m}^{2}$ ), 
shows that the connection to the green spaces happens at different levels in two suburbs. Palmerston has access to the green space through private green and in Crace that relationship is built at the public open green space. Harrison has even larger span of plot area variations ranging from 220 to $1700 \mathrm{~m}^{2}$ with an average of $482 \mathrm{~m}^{2}$. This indicates that most of the plots in Palmerston are genuine in their size and thus providing more space for the connection to ground at the private level. Furthermore, the dominant type of the building is single-family house, generating connection to the ground directly, contrasted to the apartments or townhouses. Both apartments and townhouses are designed to preserve the sense of private, that limits the connection to ground and fluidity with public space. Because of smaller plots, there is no connection to private green and due to the need to protect the privacy of the house, there is no visual connection to the public green spaces. The sense of green and perception of quality of life has been reduced with the barriers and overall generates lower sense of liveability in Crace and Harrison. Single family house is a dominant type of the buildings in Crace. There are only $11.2 \%$ of the apartment buildings. Harrison has discontinued built environment with similar ratio to single family houses with slightly larger presence of the apartment buildings (26.6\%) that compensate for large amount of open public space. Palmerston has no apartment buildings yet manages similar density as other two suburbs.

\subsection{Liveability in Crace, Harrison and Palmerston}

Potential for community life as one aspect of liveability in Crace and Harrison is achieved through public green space. The lack of private green spaces especially in the apartment buildings is overcome with abundance of the public space. That creates possibility for interaction, community gatherings and socialisation. However, Palmerston is ranked higher compared to other two suburbs from the walkability score that indicates that there is enough space dedicated for walking that increases the sense of liveability.

Table 1: Types of public-private interface.

\begin{tabular}{|c|l|}
\hline $\begin{array}{c}\text { Type of } \\
\text { public } \\
\text { private } \\
\text { interface }\end{array}$ & The public-private interface characteristics: \\
\hline 1 & $\begin{array}{l}\text { On the one side ground floor single family house with the small front yard } \\
\text { and on the other side of the street is green open public space }\end{array}$ \\
\hline 2 & The ground level single family houses on both sides with small front gardens \\
\hline 3 & $\begin{array}{l}\text { The townhouse on the one side of the street (dominantly two stories high) } \\
\text { and single-family house on the opposite side of the street }\end{array}$ \\
\hline 4 & $\begin{array}{l}\text { Townhouse types of the buildings mirrored on both sides of the street } \\
\text { dominantly two stories high }\end{array}$ \\
\hline 5 & $\begin{array}{l}\text { The townhouse on the one side of the street and open public green space on } \\
\text { the other. }\end{array}$ \\
\hline 6 & $\begin{array}{l}\text { The apartment building on the one side of the street and single-family house. } \\
\text { Apartment buildings are higher than four floors }\end{array}$ \\
\hline 7 & Apartment building on the one side and town house on the other \\
\hline 8 & The apartment buildings on both sides of the street. \\
\hline 9 & $\begin{array}{l}\text { High rise apartment building on the one side and open public green space } \\
\text { on the other side }\end{array}$ \\
\hline
\end{tabular}




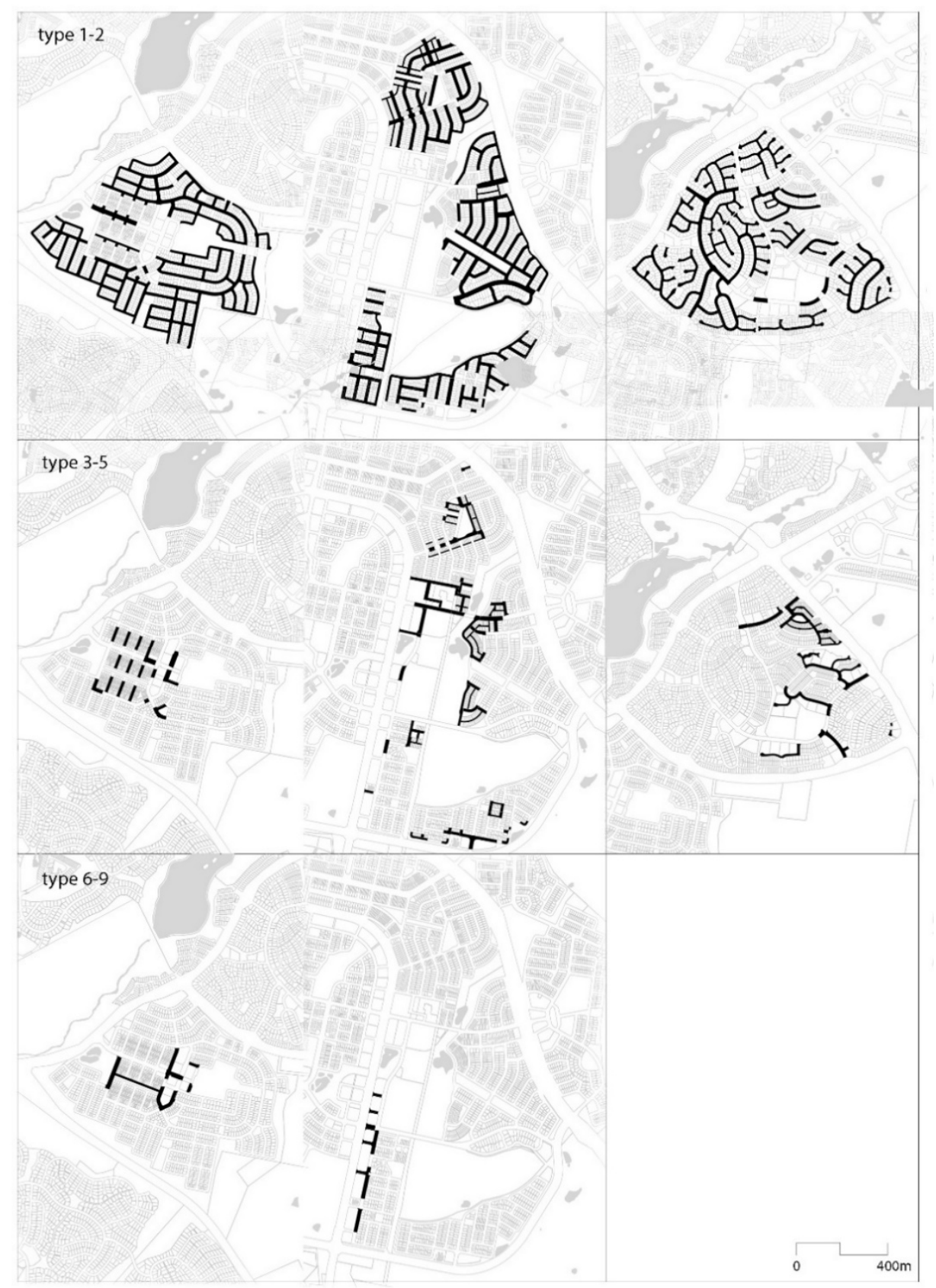

Figure 4: Distribution of public-private interface in (from left) Crace, Harrison and Palmerston. (Source: Author, based on Geospatial Data Open Catalogue 2018.) 
Human scale is analysed through types of the streets (Table 1). In Crace the human scale public private interface (type 1 and 2 ) is most dominant type $82 \%$ of all streets and a sense of connectedness and friendly built environment. With less than $4 \%$ of the public-private interface type 6-9 Crace is dominantly low rise and human scale orientated suburb (Fig. 4). In Harrison the human scale street types (1-2) are generating three clusters in space (north, north-east and south) and comprise $72 \%$ of all streets. Even though it is fairly large number of streets with dominantly low rise of the buildings, it is still quite low compared to other suburbs in Canberra. The size of apartment related types of the streets (6-9) is also less than $4 \%$ however, compared with Crace they are in clusters. Overall, in Harrison there is a sense of discontinuity of built environment and pockets of human scale spaces. Palmerston has similarly $78 \%$ of the human scale street section type creating continuous built environment. There are no types that do not relate to human scale (type 6-9).

All three suburbs have single-family house as a dominant type, the characteristic that determines liveability of suburbia and reduces the sense of sustainability. The character of public-private interface is different in all three suburbs, due to the plot sizes. This could be argued also affects the liveability.

\section{CONCLUSION}

The results have shown, that continuous urban environment in Crace has a sense of compactness contributes higher levels of liveability. Public green spaces produce potential spaces for sociability and interaction between people and environment. Human scale is achieved through single family types of residential buildings and their distribution. Even though Crace is designed to be sustainable, it is not following the idea of sustainable urban forms (compact city) but aims to generate sustainability of suburbia having dominantly single-family house typology. Considering energy efficiency and transport in the city this is not most sustainable solution. On the other hand, this type of the suburb provides liveability aspects and sense of privacy that suburbia is praised for.

Fairly small plots of land in Crace and Harrison have reduced private green spaces and public spaces are considered to bring the quality of life to the suburb. Thus, if open public spaces are those that provide necessary space for socialisation, community and liveability, then suburbs could start to explore other types of dwelling, such as apartment buildings that will provide denser and more compact built environment.

Harrison achieves similar overall density as other suburbs but consist of higher density clusters of residential buildings. Because of being more efficient in the built environment, Harrison also has large areas of green public spaces. The morphology of those spaces is contributing to discontinuous built environment. According to walkability score, Harrison could be considered as least liveable from the three suburbs which in correlation with discontinuity of the open green spaces that were found in this analysis. In addition, the abundance of open green space, demonstrates that quality and functionality of those spaces matters over the quantity.

Palmerston represents a typical suburb with dominantly single-family houses, larger plots of land and limited public spaces. Interestingly, density achieved in Palmerston is similar to other two suburbs. The continuity of built environment is also realized. According to walkability score, Palmerston is the most liveable suburb among the three cases and has the least open green space. In terms of sustainability, Palmerston has the least possibility for growth although it achieves the same density as other two suburbs that are claiming to be sustainable.

This study is narrowly framed around aspects of density and green spaces and there a need for other aspects of sustainability and liveability to be addressed. However, this study has 
confirmed that open public green spaces and public-private interface could play important role in defining the more sustainable and liveable suburbia.

Generating sustainability without losing liveability in suburbia is challenging particularly in relation to density and residential typology. However, that challenge is not based on a simple dichotomy, forcing planners and designers to choose between high-rise and singlefamily house. The challenge is how to incorporate the relationship with green spaces. The shift towards providing quality public green spaces could generate sense of liveability and community connectedness. The results from this analysis demonstrate that the ratio between public and private green needs to be considered as part of the sustainable and liveable suburbia.

\section{REFERENCES}

[1] McLennan, J., The Philosophy of Sustainable Design: The Future of Architecture, Ecotone: Kansas City, 2004.

[2] Adams, R., Reprogramming cities for increased populations and climate change. The EcoEdge: Urgent Design Challenges in Building Sustainable Cities, eds E. Charlesworth \& R. Adams, Routledge: London, pp. 30-38, 2011.

[3] 3222.0-Population Projections, Australia, 2006 to 2101. Australian Bureau of Statistics, 2008.

[4] Bugliarello, G., Urban sustainability: Dilemmas, challenges and paradigms. Technology in Society, 28(1-2), pp. 19-26, 2006. DOI: 10.1016/j.techsoc. 2005.10.018.

[5] Talen, E., Sprawl retrofit: Sustainable urban form in unsustainable places. Environment and Planning B: Planning and Design, 38(6), pp. 952-978, 2011. DOI: 10.1068/b37048.

[6] Davison, A., Stuck in a Cul-de-Sac? Suburban history and urban sustainability in Australia. Zurban Policy and Research, 24(2), pp. 201-216, 2006.

[7] Dunham-Jones, E. \& Williamson J., Retrofitting Suburbia: Urban Design Solutions for Redesigning Suburbs, Wiley: New Jersey, 2011.

[8] Hagerty, M.R. et al., Quality of life indexes for national policy: Review and agenda for research. Social Indicators Research, 55(1), pp. 1-96, 2001.

[9] Kashef, M., Urban livability across disciplinary and professional boundaries. Frontiers of Architectural Research, 5(2), pp. 239-253, 2011. DOI: 10.1016/j.foar.2016.03.003.

[10] Zanella, A., Camanho, A.S. \& Dias, T.G., The assessment of cities' livability integrating human wellbeing and environmental impact. Annals of Operations Research, 226(1), pp. 695-726, 2015. DOI: 10.1007/s10479-014-1666-7.

[11] Newton, P.W., Horizon 3 planning: Meshing liveability with sustainability. Environment and Planning B: Urban Analytics and City Science, 34(4), pp. 571-575, 2007.

[12] Dalton, T. et al., Retrofitting the Australian suburbs for sustainability. Steering Sustainability in an Urbanising World: Policy, Practice and Performance, ed. A. Nelson, Routledge: London and New York, 2007.

[13] Taylor, K., Canberra: City in the Landscape, Canberra Halstead Press and The National Capital Authority, 2007.

[14] Vernon, C., Canberra: Where landscape is pre-eminent. Planning Twentieth Century Capital Cities, ed. D. Gordon, Routledge: London and New York, pp. 130-149, 2006.

[15] Aalen, F.H.A., English origins. The Garden City: Past, Present and Future, ed. S.V. Ward, Spon Press: London and New York, 1992. 
[16] Headon, M., An ideal city. Canberra Red, Stories from the Bush Capital, eds. D. Headon \& A. MacKenzie, Allen and Unwin: Sydney, pp. 61-84, 2013.

[17] Gibbney, J., Canberra 1913-1953, AGPS Press Publication: Canberra, 1988.

[18] Conger, B.W., On livability, liveability and the limited utility of quality-of-life rankings. The School of Public Policy, 7(4), pp. 1-8, 2015.

[19] Walk Score, Cities and neighborhoods. Online. www.walkscore.com/cities-andneighborhoods/, 2018.

[20] The Canberra Spatial Plan, Canberra ACT Planning and Land Authority, 2004.

[21] Jose, J., Australian Government \& Elton Consulting, Time to Talk Canberra 2030: Outcomes Report, ACT Government: Canberra, 2010.

[22] ABC News, Is This the Happiest Suburb in Australia? 2017.

[23] Meehan, B., Amazing crace: Designing a sustainable suburb. Environment Journal, 2017.

[24] Australian Bureau of Statistics, 2016 Census QuickStats, 2016.

[25] ABC News, Crace to be carbon neutral: developers. Online. www.abc.net.au/news/ 2008-09-09/crace-to-be-carbon-neutral-developers/504138, 2008.

[26] Rogers, R. \& Power, A., Cities for a Small Country, Faber and Faber: London, 2000.

[27] Australian Government, ACT Geospatial Catalogue, Canberra, 2017. 